\title{
Sporadic Hemiplegic Migraine
}

National Cancer Institute

\section{Source}

National Cancer Institute. Sporadic Hemiplegic Migraine. NCI Thesaurus. Code C117011.

A mig raine disorder characterized by an aura that includes motor weakness and the absence of family history. 